\title{
El código atemporal: la memoria cifrada en los diagramas de Hugo Rivera-Scott*
}

\author{
Bruno Jara Ahumada \\ U. de Santiago de Chile \\ cosas.yme@gmail.com
}

Resumen

Diagramas, muestra del artista chileno Hugo Rivera-Scott, comprende una serie de dibujos abstractos que se encuentran recién el año 2014 después de dos fases de producción políticamente distantes: una primera serie pre-dictatorial y una segunda, generada en el panorama actual de la democracia chilena. El presente artículo pondrá acento en el pliegue temporal que reconecta las dos series y que, vistas como conjunto, no quedan separadas a nivel representacional. Independientemente de la intención del autor, se intentará establecer un correlato entre las marcas temporales selladas en las obras y su traducción en el campo de la memoria.

Palabras claves

Hugo Rivera-Scott, diagramas, codificación, pliegue temporal, memoria.

The Timeless Code: Encoded Memory in Hugo Rivera-Scott's Diagrams

\begin{abstract}
Diagrams, an art exhibit by Chilean artist Hugo Rivera-Scott, comprises a series of abstract drawings brought together for the first time in 2014 after two phases of politically distant production: this first from the pre-dictatorial era and the second from the current situation of Chilean democracy. This article emphasizes the temporary fold that reconnects the two series, which, placed together, display unity on a representational level. Regardless of the author's intention, the paper attempts to establish a correlation between the temporal particularities sealed within the works and their translation into the field of memory.
\end{abstract}

Keywords

Hugo Rivera-Scott, diagrams, codification, temporary fold, memory.

* Recibido: 30 de agosto de 2016 / Aceptado: 16 de noviembre de 2016. 


\section{O código intemporal: memória codificada nos Diagramas de Hugo Rivera-Scott}

Resumo

Diagramas, uma exposição de arte do artista chileno Hugo Rivera-Scott, compreende uma série de desenhos abstratos reunidos pela primeira vez em 2014, após duas fases de produção politicamente distante: a primeira da era pré-ditatorial e a segunda da situação atual da democracia chilena. Este artigo enfatiza a dobra temporal que reconecta as duas séries, que, juntas, exibem a unidade em um nível representacional. Independentemente da intenção do autor, o artigo procura estabelecer uma correlação entre as particularidades temporais seladas nas obras e sua tradução no campo da memória.

Palavras-chave

Hugo Rivera-Scott, diagramas, codificação, dobra temporária, memoria. 


\section{Introducción}

Diagramas (2014) fue una muestra de doble montaje del artista chileno Hugo Rivera-Scott en la que presentó, inicialmente en Santiago y después en Valparaíso, una serie de dibujos monocromáticos realizados en tinta china sobre papel (figuras 1 y 2). Cada una de las obras, casi todas realizadas en formatos cercanos a los $50 \times 70$ $\mathrm{cm}$, se construyen a través de un trazo lineal que configura o hace aparecer la imagen a partir de cambios direccionales y variaciones de ritmo. En total, Diagramas presentó un resumen de 44 obras en el que diferenciamos dos series: una primera, producida entre 1970 y 1972; y una segunda, creada el 2013, que insiste en las leyes configurativas de la serie original. Así, el proyecto de exhibición surge del interés por rescatar y restaurar esta primera serie de trabajos, antes parcialmente exhibidos tan solo en dos ocasiones ${ }^{1}$, expandiendo tanto su número como su proyección en el espacio mediante la creación de obras nuevas y la instalación de obras precedentes. Además, esta muestra se enmarca dentro de un proyecto que incluye la publicación del libro Diagramas: cuaderno paradocente, edición realizada en conjunto por la editorial Vaticanochico y Ocho Libros Editores².

A partir de su contenido formal, Diagramas se sitúa en un prisma que no interpela ni alude a las políticas y experiencias del trauma propias del contexto histórico de la dictadura militar. La representación que se articula en las obras no describe, por ejemplo, la violencia que grupos como la Escena de avanzada intentó instalar en la esfera nacional del arte a partir de un proceso de codificación y auto-censura. No obstante, la serie presentada el año 2014 en un mismo y único espacio temporal, está marcada irreductiblemente por la violenta interrupción que suspendió su producción. Si hoy es posible leer estas obras como una presentación de conjunto que posiciona en un mismo nivel de lectura las obras pre-dictatoriales con las obras generadas en democracia - es gracias a un efecto de superposición de dos polos temporales, distanciados, inequívocamente, por la irrupción política del régimen militar. De modo tal, que cualquier interpretación que abordara a Diagramas desde un análisis puramente visual, apenas constituiría una lectura de superficie, es decir, desvinculada del acto ético (Bajtín, 1997) que intersecta en un mismo criterio la triangulación entre ética, estética y política.

A través del análisis de este código que persiste en el tiempo, se abre pauta a las siguientes preguntas: ¿Cuál es el sentido que subyace en el intento por restablecer

\footnotetext{
${ }_{1}^{1}$ Parte de las obras fueron expuestas por primera vez en el Museo de Arte Contemporáneo de Santiago, el año 1970. Más tarde, en 1971, se expuso una sección en la I Bienal de Cali en Colombia.

2 Su primera edición, publicada en noviembre de 2013, recoge 37 dibujos y 4 imágenes de procedimiento, acompañados del texto “¿Qué es un diagrama?" escrito por el autor; parte de aquél será utilizado más adelante para analizar el objeto de estudio.
} 
una continuidad interrumpida mediante un código visual que pareciera no representarlo? ¿Por qué es posible leer, en una misma secuencia, una serie producida en distintas aristas políticas y temporalmente distantes? ¿A través de qué mecanismos intrínsecos a la obra se configuraría esta lectura? ¿En qué medida Diagramas es capaz de traducir la memoria política que truncó su producción?

La hipótesis que se examinará apunta que los dibujos que configuran la muestra Diagramas pueden transitar temporalmente, producto de un código de representación cifrado y potencialmente infinito: a través de una producción sistemática que se mantiene fiel a sus propias normas configurativas, la serie es capaz de generar infinitas combinatorias, limitadas, únicamente, por la posibilidad técnica. Por tanto, insistir en sus mecanismos, a pesar del trauma político que interrumpió su desarrollo material, guarda sentido con la idea del abandono: toda serie de diagramas es una serie que nace a la deriva de un conjunto mayor. Así, las dos instancias de Diagramas logran reconectarse según un mismo código de representación que entrelaza el desfase temporal al momento de la lectura. No obstante, el trauma político no es un elemento que quede desplazado de la obra; mediante una huella textual -el envejecimiento del papel en las piezas más antiguas - es posible leer la memoria política a partir de rasgos explícitos sellados en la memoria material del soporte. Al mismo tiempo, no es sino en su condición de conjunto que Diagramas se constituye como secuencia, invitando así a una lectura de la urdimbre memoriosa que no se configura si no es a través de una macro-composición de relatos, testimonios, experiencias y archivos.

\section{Temporalidad y memoria}

Antes de analizar el objeto de estudio, será necesario especificar la concepción de memoria en cuanto a fenómeno temporal, para después enmarcarla según la problemática política y social que nos concierne.

El filósofo alemán Martín Heidegger acuña la idea del tiempo a la existencia misma del ser humano. En su libro Ser y tiempo, de 1927, Heidegger estipula una filosofía temprana marcada por la existencia del Dasein, término que nos indica que "el hombre es el ahí (Da) del ser (Sein)" (Acevedo, 2014: 25). Es en su experiencia fáctica, por tanto, que el Ser queda manifiesto, compareciendo así la idea de una existencia coligada a un espacio-tiempo predeterminado, siempre continuo, en donde el Dasein se desenvuelve a través de lo cotidiano. Es decir, el ser humano, caracterizado por su condición temporal finita dentro de un tiempo social continuo, queda expuesto y dispuesto a Ser en un mundo preconcebido; toda experiencia del ser humano, entonces, está previamente erigida por su preconcepción fundamental en el tejido temporal del espacio social donde queda inserto. 


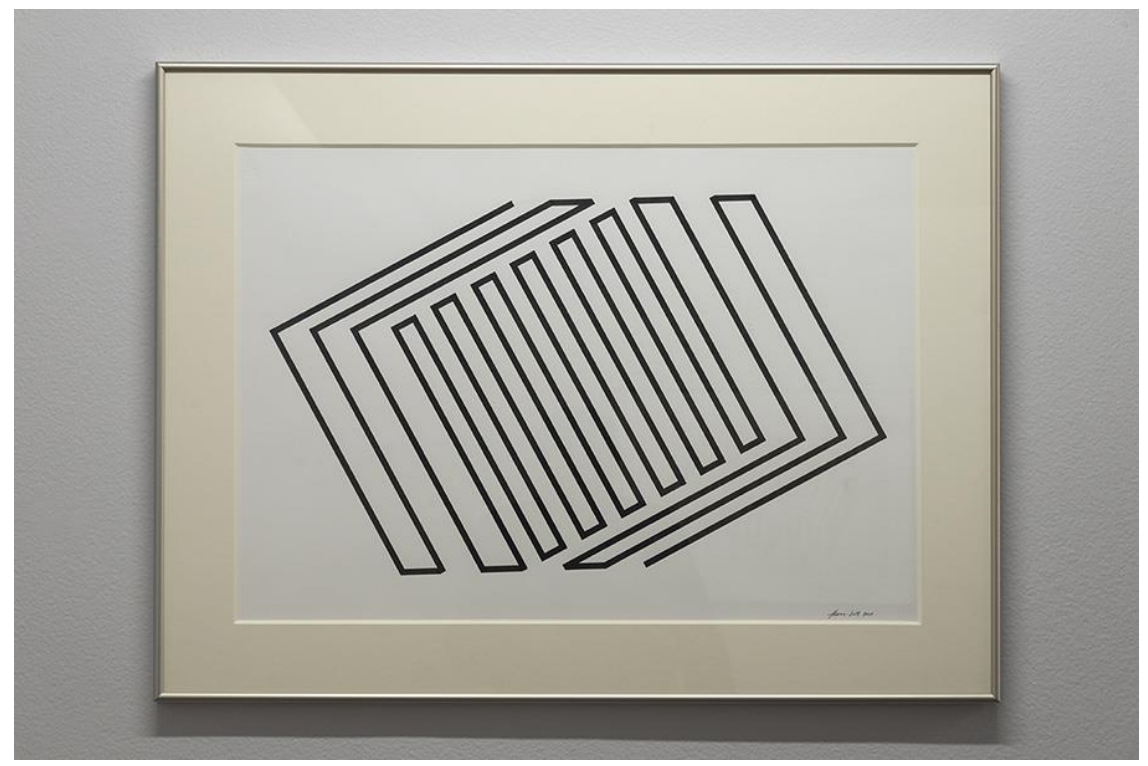

Figura 1. Muestra del montaje en la galería D21. Fotografía cortesía de Hugo Rivera-Scott.

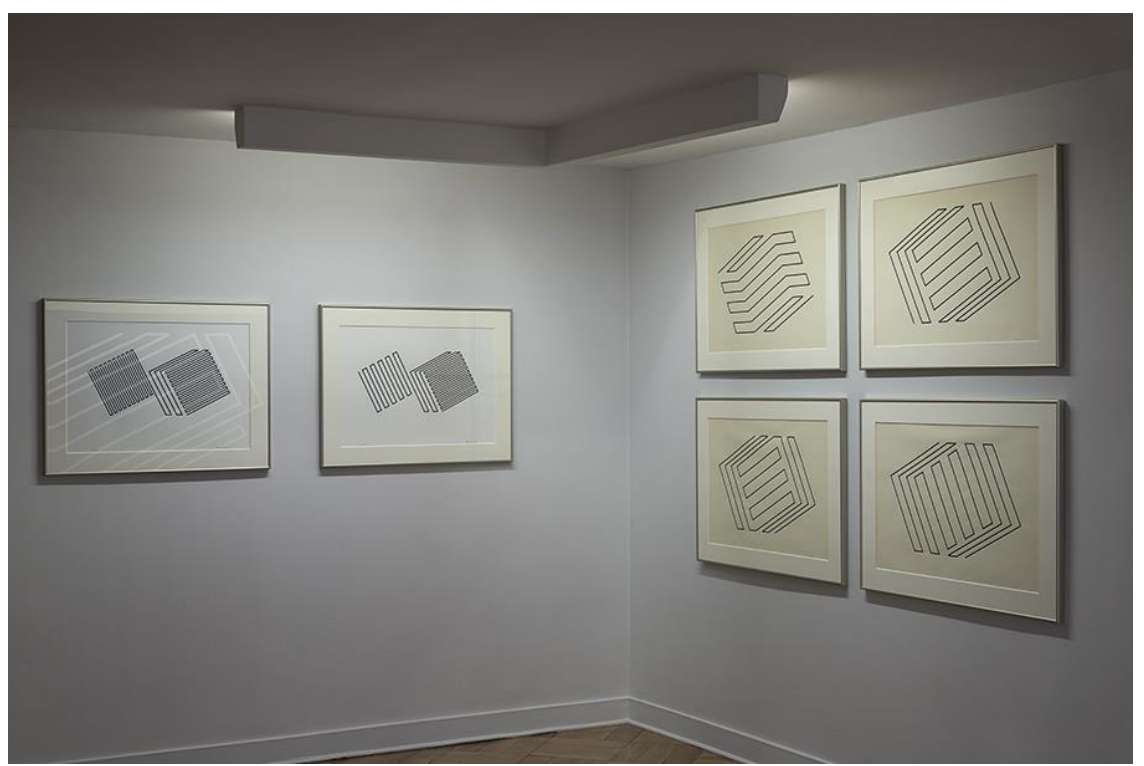

Figura 2. Seis diagramas montados en la galería D21. A la izquierda, encontramos las obras recientes "Despliegue I y II" (2013) de 50x70 cm cada una. A la derecha, vemos la serie "Forma variante I, II, II y IV" (1970) de 52x79 cm cada una. Fotografía cortesía de Hugo Rivera-Scott. 
Asimismo, cualquier posibilidad de existencia y, por tanto, también todo acontecer, se sitúa dentro de una línea temporal continua, por efímera que sea su manifestación, producto de las propias condiciones que demarcan su existencia empírica. No obstante, el tiempo y sus representaciones varían según las sociedades y también dentro de una misma sociedad, cuyo ritmo está dado por una multiplicidad de tiempos sociales (Candau, 2006: 38). Cada una de estas representaciones -cíclicas, lineales, discontinuas - alternan, en su modo particular, la modalidad de búsqueda de la memoria: "La memoria acompaña cada día de una vida humana porque no hay nada conocido que no pertenezca al pasado y que, por consiguiente, no tenga que ser memorizado" (Candau, 2006: 36). De este modo, se puede ceñir el acto memorioso a la existencia misma del Ser, en tanto se establece en el campo temporal donde se desenvuelve. Ahora bien, ¿cómo situar la memoria temporal del Ser dentro de la urdimbre política-histórica-social?

Elizabeth Lira señala que la memoria se vincula a la vida social y política en beneficio de la convivencia y la reconciliación. De ahí que las operaciones de olvido y recuerdo, condicionantes de toda existencia humana, actúen en la medida de una supervivencia colectiva, como posibilidad reparatoria de los efectos del trauma político. Sin embargo, la configuración social de la memoria aparece como una construcción consensuada que muchas veces resulta inservible ante los propósitos sanatorios:

La memoria al margen de la conciencia - de ese darse cuenta que opera como continuidad permanente en lo cotidiano - puede ser vivida como un recuerdo ajeno, sin sentido para el sujeto, y se hace inútil como recurso para el alivio de su ansiedad y temor, y, por tanto, infructuoso para la supervivencia (Lira, 2010).

Sobre lo anterior, entender las problemáticas de la memoria implica una "supervivencia" en términos de una determinación social en la que cada una de las aristas, relatos y experiencias singulares levantan una hiper-narración de carácter vivo y en constante actualización. Para Nelly Richard, la memoria del consenso post-dictatorial representa una forma particular de omisión: la oficialidad y la consagración social que profesa el Estado sobre los tópicos memoriales, no sólo apuntan a una restricción o validez de aquello que puede ser recordado, sino que también limita los modos y mecanismos en que esta pequeña fracción debe ser recordada. El "qué" y el "cómo" recordar quedan encriptados y codificados según un modelo particular de aceptación y validez histórica. Por ello, Richard acusa la necesidad de reescribir la memoria desde la mayor cantidad de fragmentos:

Para desbloquear el recuerdo del pasado que el dolor o la culpa encriptaron en la temporalidad cerrada de un ayer desvinculado del presente, deben liberarse diversas interpretaciones de la historia capaces de ensayar, a partir de las múltiples fracciones disconexas de una temporalidad conflictiva, nuevas versiones y reescrituras de lo sucedido y 
de trasladarlo a redes inéditas de inteligibilidad histórica que lo transformen retrospectivamente (Richard, 2010: 49-50).

La autora detecta la problemática latente de una memoria cristalizada por los efectos mismos de la violencia: tanto desde la perspectiva de las víctimas como desde las políticas reparativas del Estado, la historia quedó determinada y sujeta irrefrenablemente al discurso hegemónico del "nunca más". Esta concesión discursiva aglutina y aplana en un mismo relieve toda posible construcción de una memoria "al margen". Desde otra arista, podemos pensar los discursos de la memoria, según la función enunciativa propuesta por Michel Foucault, como una red de enunciados sujetos a una materialidad que los recoge y asocia en el presente; todo discurso implicaría una sumatoria de insumos múltiples: "una repartición de lenguas, de vacíos, de ausencias, de límites, de recortes" (Foucault, 2002: 156). Sin embargo, el espesor memorioso se empobrece al no admitir segmentos de extra-muros, pues, a fin de conformar un único gran relato, "cada elemento tomado en consideración se admite como la expresión de una totalidad a la que pertenece y lo rebasa" (Foucault, 2002: 155).

Para cerrar esta conceptualización, recurrimos a Sandra Navarrete, quien posiciona el debate desde la pluralidad: no es "la" memoria, sino "las" memorias las que, en simultáneo, afianzan el pasado histórico: "[...] las memorias son las distintas formas en que una sociedad le otorga significado a su pasado, conformando una zona atravesada por constantes disputas y pugnas por los sentidos que se le atribuyen a lo rememorado" (Navarrete, 2016: 6). Esta autora también alude a que, independientemente de la cantidad de segmentos que se recojan para recomponer la memoria, estas narrativas siempre se encontrarían en conflicto, ya que no sería posible imprimir un único sentido o tono a la remembranza del pasado. Se podría hablar de la memoria, entonces, como una macro-composición de segmentos, en constante re-escritura, confinada a trastocar la unicidad de la verdad histórica según un determinado tiempo social. Sin embargo, queda pendiente la pregunta por las "formas" y los instrumentos capaces de hilvanar estos relatos memoriosos.

Sobre esto, Nelly Richard, consciente de la imposibilidad totalmente reconstitutiva del orden social ya trastornado, señala que el texto artístico sería capaz de interpelar y re-ordenar los vacíos, omisiones y faltas que los medios establecidos no son capaces de reparar: "les corresponde al arte, al pensamiento estético y crítico hacerse cargo de las subjetividades rotas y de las narraciones de los dañados que carecen de poder enunciativo en las esferas de los medios de comunicación" (Richard, 2010: 183). Con lo anterior, se vuelve necesario establecer las propiedades del texto artístico y sus límites interpretativos, a fin de disponer, más adelante, de un marco que vincule al arte y la ética social dentro del análisis concreto de Diagramas. 


\section{Texto artístico e interpretación}

El texto artístico -o la obra de arte- dispone de un singular mecanismo para desencadenar el acontecer memorioso. Yuri Lotman define al arte como un lenguaje específico que se articula según los códigos del lenguaje común, entendiendo por lenguaje, a su vez, "cualquier sistema de comunicación que emplea signos ordenados de un modo particular" (Lotman, 2011: 18). Este autor denomina al lenguaje artístico como un "lenguaje de modelización secundario", el cual se sirve de la lengua "natural" para construir sus propias fronteras, leyes y normas. El lenguaje natural - por ejemplo, cualquier idioma - es el material constructivo del arte, y la obra es el texto inscrito según tal modelización ${ }^{3}$.

De este modo, el texto artístico, al constituirse como lenguaje, se instaura dentro del campo de la comunicación, en donde necesariamente se da lugar a una emisión y una recepción ${ }^{4}$. No obstante, "para que un acto de comunicación tenga lugar es preciso que el código del autor y el código del lector formen conjuntos interesados de elementos estructurales" (Lotman, 2011: 39). Estos conjuntos señalan puntos de encuentro y comparecencia, en los que acontece, a distintos niveles de profundidad, un acto interpretativo.

Umberto Eco propone una arqueología de la interpretación en donde aplica una metodología que pretende estudiar el texto o la obra de arte desde su objetividad lingüística. El autor baraja una posición interpretativa cuyos límites quedan trazados, siempre, por un triángulo definido según la intención del autor -intentio auctoris-, la intención de la obra -intentio operis - y la intención del lector -intentio lectoris. Esta geometría determina toda posible interpretación, en cuyo juego el espectador puede ir optando por alguna de las tres intenciones ${ }^{5}$. La combinatoria entre estas posiciones arroja un sinfín de interpretaciones, de las que también se bi-

\footnotetext{
${ }^{3}$ Esto no indica que el lenguaje artístico traduzca o transforme todo el espectro de códigos y signos de una lengua natural. Al contrario, el texto artístico logra emitir un volumen de contenidos que no serían transmisibles a través de una lengua natural. El código del lenguaje artístico compete a su estructura misma, la cual se configura según sus propias leyes y no es capaz de ser traducida sin sufrir, al menos, una transformación radical, a una lengua natural.

${ }^{4}$ Se debe tener presente que los sujetos de dichas variables pueden coincidir en un mismo individuo o grupo social, acaso únicamente distanciados por un espacio temporal.

${ }^{5}$ Esto quedaría sujeto a distintos factores de la comunicación tales como el manejo del código, la presencia de ruidos en los canales de transmisión, la situación enunciativa, etcétera.
} 
furcan, inevitablemente, tergiversaciones del sentido. Así, se entrecruzan una diversidad de significaciones múltiples o unívocas, coherentes o disconexas, que, en suma, logran ampliar la estructura inicial de la obra ${ }^{6}$.

Desde otro punto de vista, Foucault problematiza la interpretación y la rechaza, en tanto "interpretar es una manera de reaccionar a la pobreza enunciativa y de compensarla por la multiplicación del sentido; una manera de hablar de ella y a pesar de ella" (Foucault, 2002: 158). Con lo anterior, Foucault resta importancia al momento de la enunciación, resituando el foco en el enunciado mismo y su materialidad. A su vez, Foucault entiende por enunciado el elemento último, la unidad mínima de un discurso. Sin embargo, éste no remite a una forma específica o a un cuerpo determinado, cual signo lingüístico: "el dominio enunciativo está todo entero en su propia superficie. Cada enunciado ocupa en ella un lugar que sólo a él pertenece" (157). Se trata, entonces, de encontrar el soporte donde los enunciados, al articularse, materializan cierta objetivación cultural. En vista de ello, Foucault propone un sistema que, con el hábito, lograría "arrancar el discurso pasado a su inercia y volver a encontrar, por un instante, algo de su vivacidad perdida" (161-162). De este modo, en la lectura de los enunciados deberían buscarse las "marcas" impregnadas en el soporte y que, al ser descifradas, desencadenarían los procesos de memoria ya no desde una posición meramente interpretativa, sino indagando en los "rastros" del origen perdido. Se debe examinar, por tanto, "qué modo de existencia puede caracterizar a los enunciados independientemente de su enunciación" (162). Así, Foucault conjetura que los enunciados deben ser "considerados en la remanencia que le es propia" (162). La remanencia, por su parte, supone que los enunciados no sólo están enmarcados en el campo de la memoria, sino que lo están gracias a la conservación por medio de cierto número de soportes y de técnicas materiales, según ciertos tipos de instituciones y con ciertas modalidades (162). Esto quiere decir que las cosas ya no poseen el mismo modo de existencia que en su origen enunciativo y que, para volver a ellas, se debe indagar en los factores que "sellaron" estos enunciados. Aquello que fue olvidado o destruido no posee presencia y, así, "el olvido y la destrucción no son, en cierto modo, sino el grado cero de esta remanencia" (163). Desde el fondo que constituye la remanencia, pueden desplegarse los juegos de la memoria y del recuerdo.

Para finalizar, hemos trabajado el concepto de texto artístico según la teoría de Lotman y hemos delimitado su región interpretativa en base a las tres intenciones propuestas por Eco. Al mismo tiempo, considerando al texto artístico como una

${ }^{6}$ A pesar de que toda interpretación y tergiversación es válida en sí misma, ciertamente existen interpretaciones que se desenmarcan de la coherencia textual de la obra, por tanto, existirían interpretaciones más apropiadas que otras. Así, las interpretaciones "menos atentas" son aquellas que no quedan contenidas dentro de esta esfera. 
trama de enunciados, hemos puesto el foco en su materialidad, su soporte y su capacidad de remanencia, al estudiar los análisis de Foucault. De este modo, podremos analizar en qué medida Diagramas, en cuanto a sistema de enunciados, logra conectar, a través de huellas y evidencias físicas, la instancia de su emisión original con su momento de recepción en el presente.

\section{Diagramas, arte y ética}

Como hemos mencionado previamente, las dos fases de Diagramas superponen la cualidad de lo irresuelto. Hugo Rivera-Scott señala que "los diagramas son una serie que, al haber quedado interrumpida, también quedó abierta, sin conclusión" (2013: 56). En efecto, tanto la primera serie como la segunda confirman la potencialidad expansiva del conjunto. La serie inicial habría sido efectuada a raíz de una reflexión crítica y, a la vez, bastante concreta, que Rivera-Scott desarrolló respecto al dibujo y sus alcances. Al mismo tiempo, esta reflexión constituyó una extensión del trabajo monocromático que habría estado realizando en pintura abstracta, durante la década del sesenta y los primeros años del setenta. Por otra parte, la nueva propuesta curatorial se inició, en primera instancia, como un proyecto editorial: las 21 obras que sobrevivieron a la dictadura y a los aprietos del exilio, debidamente conservadas dentro de una carpeta, constituyeron un acervo que llamó la atención de Vaticano Chico editores, quienes, tras la insistencia, encaminaron un proyecto que finalmente se objetivaría en un pequeño libro llamado Diagramas: cuaderno paradocente (2013) ${ }^{7}$. Esta publicación habría servido como un motivo para restaurar las piezas originales y elaborar obras nuevas, las cuales, sumadas a las demás, manifiestan una intención clara por reactivar y retomar un trabajo en suspenso ${ }^{8}$.

Finalmente, el proyecto editorial decantó el año 2014 en una propuesta de exhibición doble: un primer montaje, con un número menor de obras, fue exhibido en la galería D21 de Santiago, entre el 10 de julio y el 14 de agosto de aquél año (ver figura

\footnotetext{
${ }^{7}$ El título del libro guarda relación directa con la labor académica que Hugo Rivera-Scott realizó en la Escuela de Arquitectura de la Universidad de Chile, sede Valparaíso. Primero, entre 1970 y 1971, como profesor de Color, y luego, entre 1971 y 1973, como profesor y jefe de la carrera de Pedagogía en Artes Plásticas en la misma universidad. El fundamento teórico que sustenta a Diagramas se habría originado entre su actividad artística y su relación con el aula, rol que sigue efectuando como profesor del Departamento de Diseño de la Universidad de Chile.

${ }^{8}$ Cabe destacar que el artista no abandonó la producción artística tras el exilio, sino que, pese a verla significativamente reducida, recondujo sus propuestas: un primer factor decisivo tuvo que ver con la incapacidad de contar con los mismos insumos e instrumentos básicos con los cuales desarrollaba la serie original de Diagramas. Otro factor determinante radicó en el contexto político, cuya permeabilidad dentro de la vida del autor replanteó, en esa determinada laguna temporal, los sentidos representativos de la abstracción geométrica. Por esta razón, el trabajo que Hugo Rivera-Scott realizó durante el exilio se adscribió a un dibujo figurativo y simbólico, corpus que, al menos en esta instancia, no formará parte del análisis.
} 
3). Poco tiempo después, la muestra se montó en el Parque Cultural de Valparaíso ampliada tanto en el número de diagramas como en la introducción de obras precedentes - entre el 12 de septiembre y el 30 de octubre (ver figura 4). En términos museográficos, el autor planteó una contigüidad cromática a partir del azul, matiz extraído de una pintura previa que puso a dialogar junto a los dibujos. Al mismo tiempo, esta pintura monocromática, junto a la actividad docente del artista, formó parte de los antecedentes formales y conceptuales más directos de Diagramas. Junto con ello, se distingue el emplazamiento de una escultura de piso $^{9}$ y de instalaciones complementarias de video, registro fotográfico y pintura in situ realizada según la misma clave cromática (ver figuras 5 y 6 ).

Habiendo descrito el panorama curatorial de Diagramas, nos preguntamos: ¿En qué medida esto nos ayuda a dilucidar nuestras conjeturas sobre la obra y la memoria social? La apertura de la serie en sus dos fracciones temporales - previas y posteriores a la dictadura - nos sirven para indicar la franja intermedia: la creación artística durante el régimen dictatorial. Si bien la producción de Diagramas - suspendida por el exilio del autor - no se origina desde aquella sección temporal, será necesario entender, a fin de establecer una zona de contraste, de qué modo los artistas nacionales re-estructuraron sus obras y procedimientos en ella.

Tras el golpe militar, la nueva organicidad social obligó a los artistas que permanecieron en Chile a reformular sus metodologías de producción. Tras un proceso de censura - por parte del poder oficial-, los artistas se sometieron a un procedimiento de autocensura a fin de condicionar las obras a un código "secreto". De este modo, el arte producido en el Chile de la dictadura fue incapaz de trabajar según los mismos medios preestablecidos, lo cual repercutió en la conformación de nuevos lenguajes que respondieran, indirectamente, al horror inefable del cual eran víctimas: "una vez desarticulada la historia y rota la organicidad social de su sujeto, todo deberá ser reinventado, comenzando por la textura intercomunicativa del lenguaje que, habiendo sobrevivido a la catástrofe, ya no sabe cómo nombrar las cosas" (Richard, 2014: 16).

Grupos como la Escena de avanzada o el C.A.D.A. re-escribieron el lenguaje y las formas para cifrar sus contenidos de denuncia, de modo que las obras lograran subsistir en la escena local sin ser eliminadas o silenciadas. En términos de Lotman, el arte, que ya es un lenguaje secundario, se habría retraído en sí mismo y vuelto a codificar, modelizando así otra capa de entendimiento superior y más compleja aún que el arte tradicional: "al transgredir los límites convencionalmente fijados por las disciplinas, el arte metaforizaba el deseo de querer abolir las reglas aprisionadoras de la experiencia que clausuraban todos los horizontes de la vida" (Richard, 2014: 17).

${ }^{9}$ Por concepto de espacio, la escultura de piso fue emplazada únicamente en el Parque Cultural de Valparaíso. 
Bruno Jara. El código atemporal: la memoria cifrada en los diagramas de Hugo Rivera-Scott.

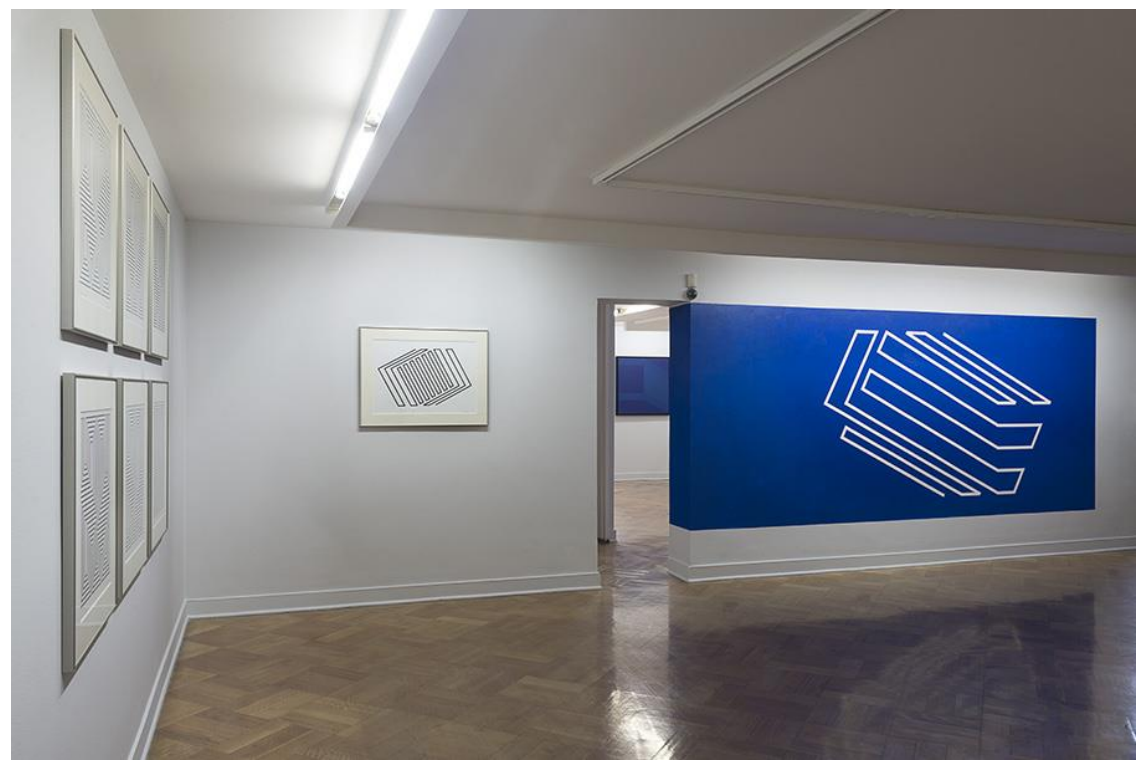

Figura 3. Vista de la exhibición en la galería D21, Santiago. Fotografía cortesía de Hugo Rivera-Scott.

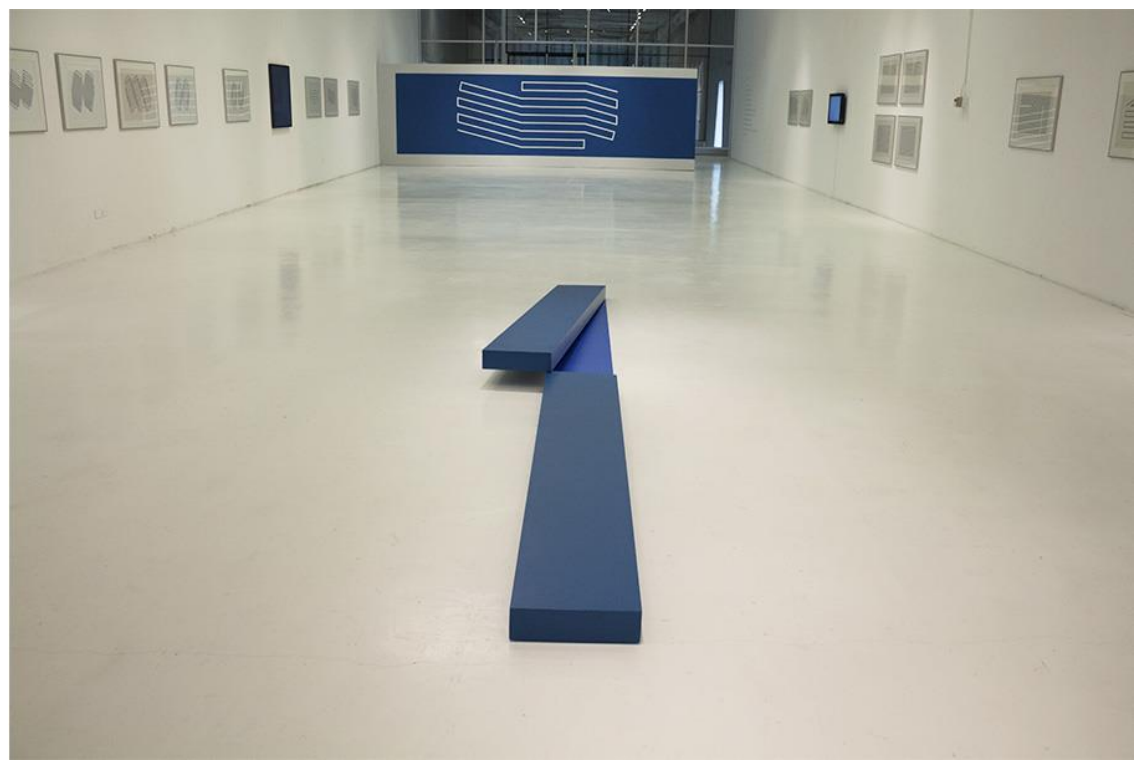

Figura 4. Exhibición en el Parque Cultural de Valparaíso. Fotografía cortesía de Hugo Rivera-Scott. 


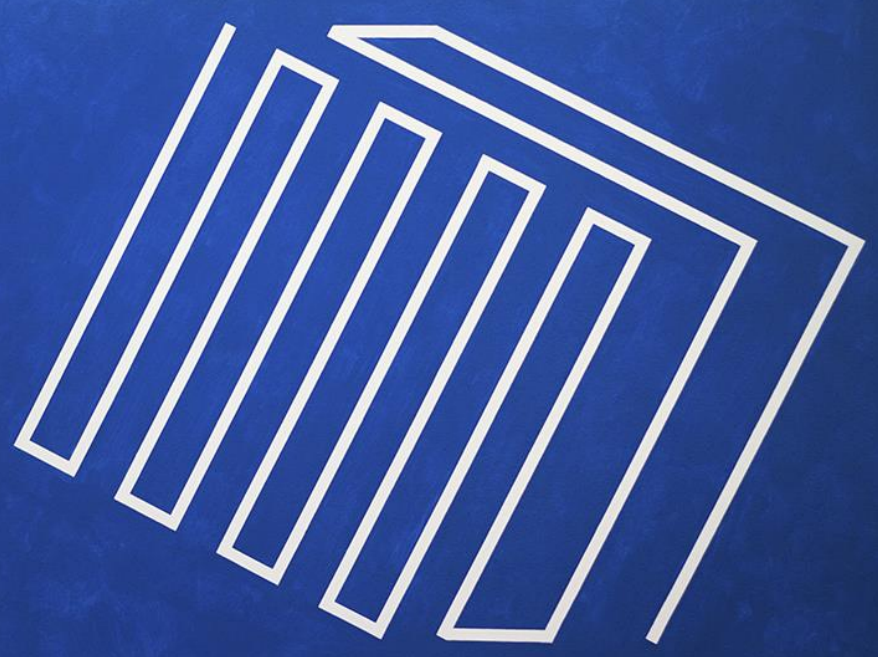

Figura 5. Pintura in situ emplazada en un muro de la galería D21. Fotografía cortesía de Hugo Rivera-Scott.

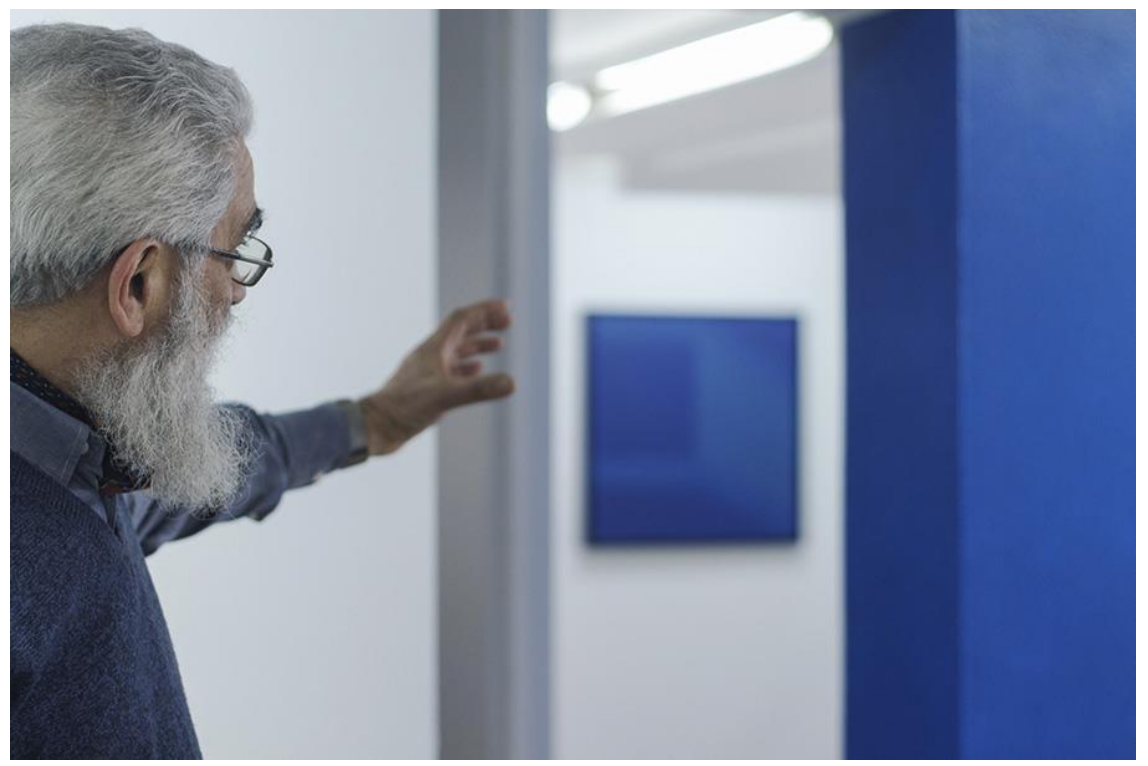

Figura 6. El artista Hugo Rivera-Scott. Al fondo, pintura monocromática cuyo matiz reaparece en la museografía de ambas exhibiciones. Fotografía de Dai Liv Fuentes Araya. 
Aplicando los términos interpretativos de Eco, se puede señalar que la intención de los autores cuyas producciones quedaron inscritas en la dictadura militar -intentio auctoris - , fue la de resistir a los efectos de la violencia mediante la codificación de sus obras, provocando una borradura de las fronteras artísticas o de los medios -intentio operis. No obstante, este conjunto de representaciones, que encriptaron metafóricamente su mensaje, luchaba contra una recepción internacional -intentio lectoris - que les obligaba a delatar directamente el trauma, el dolor y la herida:

El pedido [...] que el circuito metropolitano les dirigía a estas obras chilenas nacidas bajo censura y represión, quería de hecho obligar al arte de la contra-dictadura a la denotatividad de un mensaje que sólo debía expresar la violencia del síntoma histórico (Richard, 2014: 20).

Mientras la hipercodificación de los enunciados artísticos formulados en dictadura obligaba al espectador a realizar operaciones de rastreo con el fin de desenterrar el sentido oculto que el régimen militar obligó a esconder, Diagramas describe una función enunciativa en la que los códigos de representación no se ven alterados. La violencia y sus efectos no trastocan el lenguaje o los enunciados de la obra; al contrario, éstos continúan su desarrollo en la posteridad. Por tanto, surge nuevamente la pregunta que abrió esta investigación: ¿cuál es el sentido que subyace en el intento por restablecer una continuidad interrumpida mediante un código visual que pareciera no representarlo? $Y$, frente a ello, ¿cómo se puede hablar desde una postura ética?

En contraste con el arte producido durante la dictadura, esta serie particular de Hugo Rivera-Scott se desentiende formalmente de sus procedimientos y fines representativos. Cada uno de los dibujos que conciernen a Diagramas responden a unidades que se validan formalmente en sí mismas: no remiten a una violencia externa ni intentan codificar una denuncia secreta. Desde la intentio operis podemos conjeturar que la serie actúa desde la abstracción pura, tornándose un ejercicio analítico sobre el dibujo y sus posibilidades, más que el efecto reflejo del panorama social intermedio a su propia producción. Adorno entiende que toda obra de arte es un producto cultural, en tanto es producida en la sociedad y confinada para ella. "Las obras de arte son capaces de apropiarse de lo heterogéneo a ellas, su enredamiento en la sociedad, porque ellas mismas son al mismo tiempo algo social" (Adorno, 2004: 389). Sin embargo, este enredamiento se desarrolla desde la praxis artística o la concreción misma de la obra, sin que su situación enunciativa tenga que estar forzosamente en concordancia con su entorno social, pues, pese a cualquier distanciamiento, la obra siempre caerá dentro de la trama política-social en donde aparece. El arte "no tiene que pedir perdón por no actuar directamente: no podría, aunque quisiera; el efecto político de las obras 'comprometidas' es muy incierto" (Adorno, 2004: 
379). Así, la desproporción y la densidad del trauma social no podrían traducirse fielmente en las obras, las que actuarían reduciendo el espesor de la catástrofe a meros acercamientos y disfraces. En su intento, todas estas aproximaciones se maquillarían de cinismo: "en la cultura resucitada tras la catástrofe, el arte adopta algo ideológico mediante su existencia pura, antes de todo contenido" (Adorno, 2004: 383). Se debe cuestionar, por tanto, que las obras de arte intervengan políticamente: "si eso sucede, suele ser periférico para ellas; si aspiran a eso, las obras de arte suelen quedar por debajo de su concepto" (Adorno, 2004: 394). La trampa del cinismo presupone una culpa de cuya esfera la obra no podría escaparse. Su expresión, en cuanto a presencia temporal, se revela como una cicatriz social.

Diagramas interpela al arte producido en dictadura al diferenciarse de él. Los dibujos de Rivera-Scott no encriptan más que su propia figura. Esta posición podría ser fácilmente interpretada como una negación del conflicto político, la evasión o el miramiento ofuscado hacia una realidad histórica que no estaría "tocando" a la obra. No obstante, los dibujos de Diagramas se desvían del horror y, en este ejercicio, parecen potencialmente más decidores de la catástrofe que las obras cuyos contenidos de denuncia son evidentes: éstas, al contrario, se cierran en sí mismas y en una única instancia de enunciación en la cual adquieren peso y validez histórica. Diagramas, en cambio, transita de modo paralelo al discurso ético predominante, lo cual, en cierta medida, le otorga una remanencia que puede distanciarse mucho más allá de la situación enunciativa original, siendo capaz de proyectarse, por ejemplo, al plano actual de la democracia chilena. Su sentido ético recae justamente en la representación "asocial" que no intenta expiar su propia culpa, en tanto se constituye como obra de arte. A través de ejercicios y reflexiones puramente formales, Diagramas no evade las políticas de la tortura y el horror, sino que, mediante un acto de silencio, las construye desde la inserción dentro de un espacio temporal que las implica y las contiene. Desde la obra misma, desentendiéndonos de la intentio auctoris, la falta de denuncia se sitúa como una denuncia aún más fuerte, quizá menos explícita, pero necesariamente decidora de un tiempo social que lo atraviesa y lo configura. Esta presencia social, sin embargo, queda oculta a los ojos de la recepción, ya que la misma obra la evade. Para detonar su contenido memorioso hace falta, por tanto, una pesquisa que detecte las marcas temporales de la obra: las huellas remanentes que facultan la concreción de una lectura ética, pues "la esencia social del arte le está oculta al arte mismo y tiene que ser recuperada por la interpretación" (Adorno, 2004: 380). Sin embargo, esta interpretación deberá tomar en cuenta tanto la recepción del presente como las marcas textuales de su enunciación original, el margen del rastro físico que selló su remanencia. 


\section{El código atemporal}

Al presentarse como una serie de conjuntos, Diagramas re-integra en un mismo momento y espacio temporal dos secciones políticamente distantes. Desde la intentio lectoris, el espectador es capaz de leer de una sola vez la totalidad de las obras como si se tratara de un único momento enunciativo, incluso cuando existen marcas evidentes que las distancian. Sobre estas marcas, no obstante, se volverá más adelante. En lo que sigue, compete responder lo siguiente: ¿por qué es posible leer, en una misma secuencia, una serie producida en distintas aristas políticas y temporalmente distantes? ¿A través de qué mecanismos intrínsecos a la obra se configuraría esta lectura?

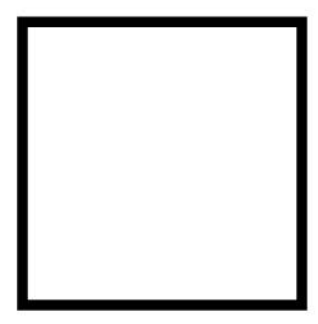

Dibujo A

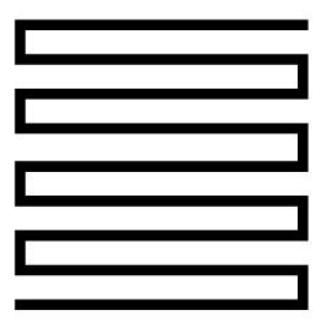

Dibujo B

Figura 7. Dibujo de contorno (A) y dibujo de conformación (B). Interpretación digital del esquema trazado por el autor en Diagramas: cuaderno paradocente. Elaboración propia.

Las obras de Diagramas comprenden dibujos angulares formados por una línea continua que, al plegarse y replegarse sobre sí misma, conforma una imagen. El dibujo, por tanto, no es descriptivo: no señala o remite a un objeto particular que haya sido contorneado. Son, en cambio, ejercicios que "hacen aparecer" a un objeto que carece de referencia concreta o material. Las palabras "configurar" y "conformar" suponen que la imagen - por ejemplo, un cuadrado- no se manifiesta según un trazo que circunda su borde - sus cuatro lados-, sino que se genera por una línea que "rellena" el espacio limitado por la forma. En la figura 7 podemos ver graficada esta relación; mientras que 
el esquema A implica un dibujo descriptivo o de contorno, el esquema B representa lo que Rivera-Scott entiende por un dibujo de conformación: "la línea del dibujo no es exactamente la imitación de las líneas del objeto, sino más bien la huella de un gesto que captura y expresa la forma" (Rivera-Scott, 2013: 66). Se llamará "diagrama", entonces, a esa particular modalidad expresiva:

Este dibujo es un diagrama: el rasgueo del trazo que lo conforma define o nombra igualmente un cuadrado, pero no como una descripción, sino que lo hace dándole materialidad al plano, haciéndolo aparecer, generándolo o configurándolo, palabra esta última que me gusta más (Rivera-Scott, 2013: 62).

Este lenguaje particular - el diagrama - describe un texto artístico potencialmente infinito. La imagen es capaz de adoptar distintas modulaciones de configuración limitadas únicamente por la técnica y la praxis. Así, se puede hablar de Diagramas como una serie predispuesta al abandono. Todo diagrama es la sombra de un grupo mayor e inacabable. Esta variabilidad, sin embargo, persiste en la idea de conjunto como consecuencia de una raíz, de una esencia aglutinadora que los mantiene como "partes de un todo" y no como secciones inconexas entre sí. Este código base soporta la coherencia textual de las obras individuales y las anuda en una misma secuencia, incluso cuando podríamos conjeturar la existencia de distintas intenciones en ellas:

Inicialmente el concepto de diagrama se logró mediante una línea sin interrupción, pero una sola. Luego, como todo proceso, esto se fue haciendo algo más complejo y fui agregando elementos separados pero unidos en su relación, lo que he visto siempre más bien como una construcción de "constelaciones" (Rivera Scott, 2013: 68).

Así, el código cifrado que traduce la colectividad de partes en un relato general se articula a partir de lo siguiente: (1) soporte de papel blanco cuya dimensión bordea los $51 \times 72$ centímetros, salvo contadas excepciones ${ }^{10}$; (2) dibujo que "configura" la forma a partir de un trazo lineal ininterrumpido o que, en su discontinuidad, pareciera serlo; (3) esta línea se dibuja en base a tinta china negra; (4) ausencia de curvas en el recorrido visual que traza; (5) para

\footnotetext{
10 Por lo general, las obras utilizan el pliego de papel completo. De este modo, los dibujos anteriores a la dictadura miden $52 \times 79 \mathrm{~cm}$ mientras que los más recientes tienen una dimensión de $50 \times 65 \mathrm{~cm}$. Sobre lo anterior, se podría conjeturar que el artista cambió los insumos con los que trabajaba o bien ya no pudo encontrar los mismos una vez que retornó del exilio. Al mismo tiempo, se distinguen nueve obras que presentan dimensiones radicalmente distintas: "Pequeño dibujo" (1973) de 23,5x52 cm; "Friso" (1971) de 29×58,5 cm; "Construcción" (1971), de 35x56 cm; "Construcción doble" (1972), 49x47cm; y la serie de "Recontrucción I, II, II, IV y V “(1970-2012), de 52×50 cm cada una.
} 
configurar la imagen, la línea sufre pliegues y repliegues en sí misma a través de ángulos (por lo general ángulos rectos); (6) un constante juego entre figura y fondo en el que ambos tienden a confundirse o entremezclarse.

Por lo tanto, es posible leer estas obras discontinuas en un mismo instante interpretativo, ya que permanecen fieles a este código. En la intentio lectoris encontramos esta secuencia emplazada en un único espacio temporal que, de este modo, enlaza los desfases de una producción torcida por la violencia militar. Los mecanismos, por tanto, que permiten establecer esta secuencia lógica están en la formulación misma de la obra como signo perteneciente a la red de enunciados que los configuran. El código adquiere la textura de lo atemporal, puesto que, independientemente del horror padecido, logra trasladarse en ambos tiempos sin sufrir cambios significativos. Las obras de un polo histórico son perfectamente compatibles con las del polo opuesto. Es más, las obras se continúan y comunican explícitamente, como sucede en "Forma variante II" (1970) y "De través III y IV" (2013) (figuras 8, 9 y 10, respectivamente); "Extensión de través I" (1970) y "Extensión de través II" (2013) (figuras 11 y 12). En esta misma línea, vemos una semejanza entre "Construcción doble" (1970) (figura 13) y la serie de "Reconstrucciones", desarrolladas el año 2012 como un ejercicio que reinterpreta un conjunto importante de obras perdidas en la década del setenta (figura 14).

El tiempo continúa paralelo a la violencia política. Toda ruptura de la organicidad social, por fragmentarios que sean sus efectos, tensiona la linealidad de un tiempo que no se detiene al margen de la existencia del trauma. El código atemporal que subyace en Diagramas no señala una "atemporalidad" como la negación de la continuidad del acontecer histórico. Más bien, lo atemporal establece un parámetro de interpretación en donde la cantidad de enunciados, potencialmente infinitos, pueden llegar a remitir a una misma intención. El código cifrado les otorga a los Diagramas una estructura de similitud, proximidad y cierre (Arnheim, 1957) que los configura en una misma ley de agrupamiento. Como conjunto, las capas temporales quedan acopladas e indiferenciadas en el mismo instante en que las obras son presentadas como una secuencia autónoma al desfase. Así, la lectura posiciona en un mismo nivel obras temporalmente distantes, con intenciones y contenidos heterogéneos que, sin embargo, en ningún caso se desprenden del "todo" que las une. 


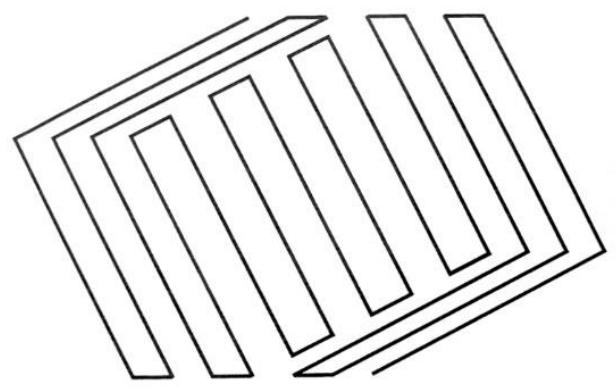

Figura 8. "Forma variante II" (1970) $52 \times 79 \mathrm{~cm}$ (Rivera-Scott, 2013).

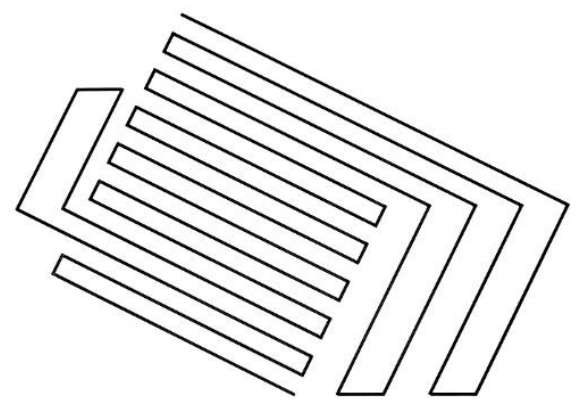

Figura 9. "De través III" (2013) 50x65 cm (Rivera-Scott, 2013).

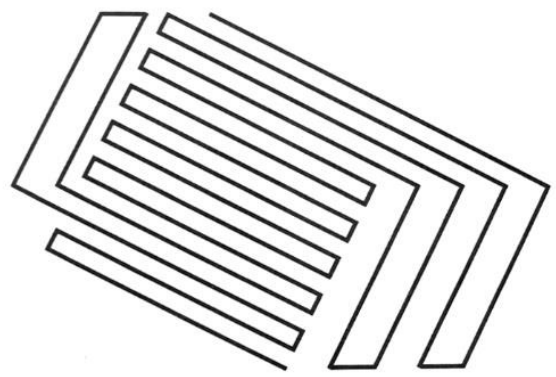

Figura 10. "De través IV" (2013) 50x65 cm (Rivera-Scott, 2013). 


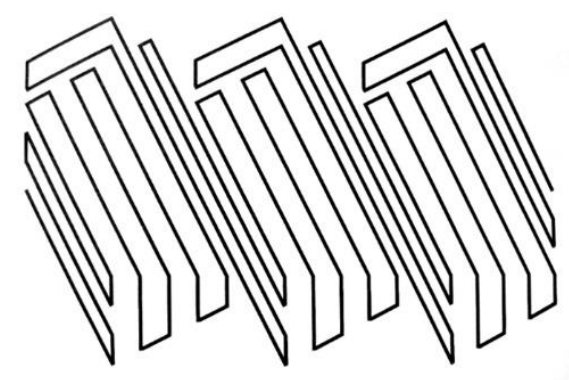

Figura 10. "Extensión de través" (1970) $52 \times 79$ cm (Rivera-Scott, 2013).

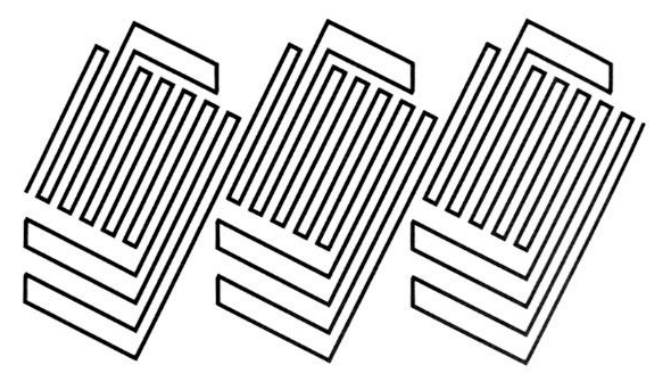

Figura 11. "Extensión de través II" (1970) $50 \times 70 \mathrm{~cm}$ (Rivera-Scott, 2013).
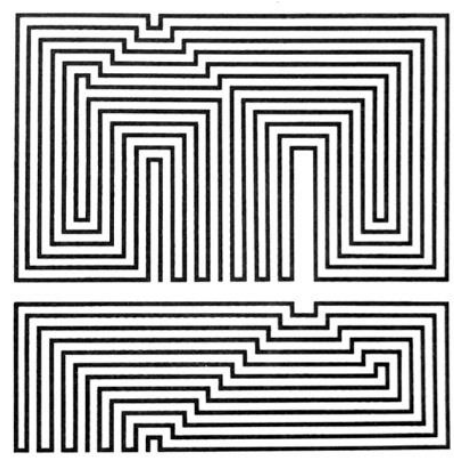

Figura 12. "Construcción doble" (1970) 49x47cm (Rivera-Scott, 2013). 


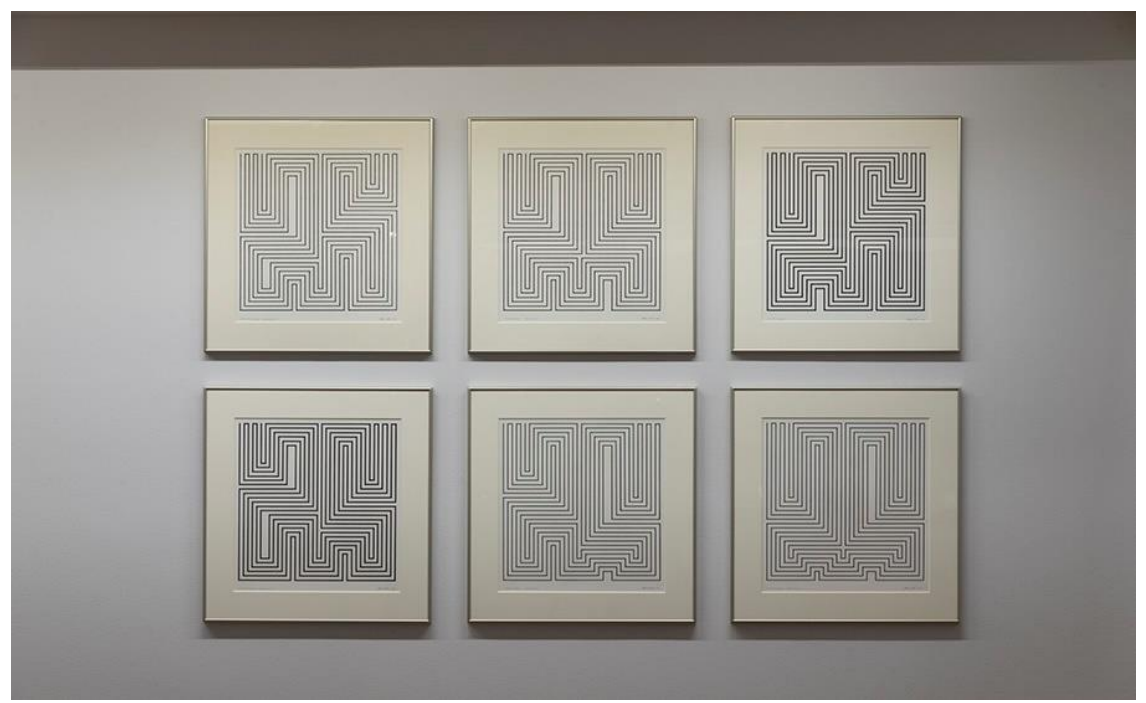

Figura 13. Serie "Reconstrucción". Arriba, I, IV y VI. Abajo, V, II y III. $52 \times 50 \mathrm{~cm}$ cada cuadro. Fotografía cortesía de Hugo Rivera-Scott.

\section{La memoria cifrada}

Los análisis previos han situado a Diagramas como una serie de dibujos cuyo contenido ético las desentiende de los enunciados artísticos producidos durante la dictadura militar; éstos, a pesar de confundir y camuflar sus mensajes, trabajaron a partir de una denuncia encubierta que debía quedar contenida dentro de sus márgenes. En este sentido, se ha señalado que Diagramas es una serie que se valida por su propio juego formal, despojándose así del compromiso social "culposo" que hemos analizado según la teoría de Adorno. Se ha dicho también que las obras que componen Diagramas son capaces de reconectarse en el tiempo, a propósito del código que las configura. No obstante ¿en qué medida Diagramas es capaz de traducir la memoria política que truncó su producción?

La figura 15 nos muestra una fotografía que ilustra una sección del montaje expuesto en la galería D21. A la izquierda se exhibe la obra "Cuerpo extendido" (2013), mientras que a la derecha se posiciona "El motivo del plano" (1971). En comparativa, las obras manifiestan diferencias cualitativas de composición y trazo. Sin embargo, éstas pueden ser entendidas como partes de un todo general en donde las diferencias quedan soportadas según la coherencia del código que las construye. Fuera de anteponer una semiótica que las divida, la fotografía captura las marcas textuales mediante las que podemos elucubrar no sólo los 43 años que distancian sus momentos de producción, sino también el devenir memorioso que clausuran en el soporte: las marcas en el papel. 

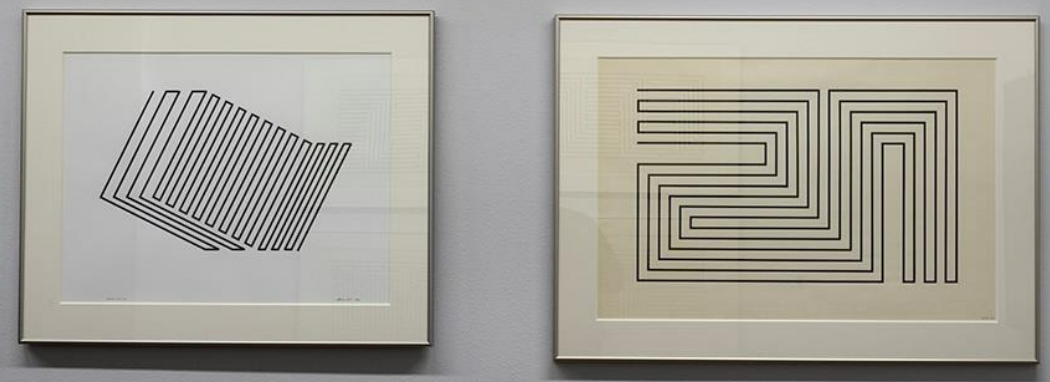

Figura 15. "Cuerpo extendido" (2013), 50x65 cm, y "El motivo del plano" (1971), 52x79cm. Fotografía cortesía de Hugo Rivera-Scott.

Como antecedente, Hugo Rivera-Scott conservó la primera serie de dibujos mediante una carpeta que trasladó consigo al exilio y con la cual también regresó a Chile, 17 años después:

Esta circunstancia permitió que se mantuviera completa sin que sus piezas se dispersaran, más allá de las pérdidas que tuvo anteriormente, o que se deterioraran, más allá de las inevitables señas del tiempo sobre el soporte del papel (Rivera-Scott, 2013: 56).

La conservación de las obras en la carpeta permitió que su función enunciativa se prolongara y se emplazara materialmente en el presente político. En base al concepto de remanencia, Diagramas encontraría un soporte técnico que opera como vehículo temporal, marcado ineludiblemente por la distancia que nos separa de su producción. Así, las señales temporales graficadas en el envejecimiento del papel nos ayudan a conjeturar la historia oculta, el antecedente "perdido" que la representación misma no estaría develando. Tal como la violencia militar dejó estragos y marcas imborrables en la retina social y, particularmente, en la memoria de las víctimas, las huellas de remanencia en Diagramas dialogan con ese pasado irrenunciable, sin rehusarlo ni investirlo de disfraces. El devenir histórico se hace materia en la obra; más aún, se vuelve enfermedad y dolencia al amenazar la perpetuación del soporte y por tanto de la memoria. La hendidura política yace totalmente expresa en Diagramas, pero no es evidente. Los signos del tiempo social quedan sellados y dispuestos a ser interpretados; la voluntad aquí, no obstante, no es la de cifrar lo inexpresable, de camuflar lo temible. El tiempo y sus efectos se ciernen en el tejido 
de la obra y se compenetran en él sin jamás retraerse, pero quedan instaurados en una segunda capa de lectura: la primera, por tanto, incumbiría a la imagen formal y la reflexión visual que plantea el autor. La segunda capa, inmediatamente posterior a la imagen, pertenece al fondo crudo, sin tinta, que revela la fibra amarillenta del soporte. Así como en los dibujos de Diagramas el fondo y la figura juegan a un constante intercambio de roles, donde ambos elementos, con igual valor, conforman en simultáneo la obra resultante, la memoria social realiza un gesto que superpone incesantemente el ir y venir de relatos y "formas" memoriosas sobre un "fondo" o franja de tiempo que deja entrever las huellas de la catástrofe. El tiempo y los modos de pensar el recuerdo reestructuran conjuntamente las formas discursivas de la memoria: el efecto de las obras de arte, en cuanto a formas de modelización, es el del recuerdo que producen mediante su existencia (Adorno, 2004: 394).

Con lo anterior, entonces, habría que especificar lo "atemporal" de su código: es el lenguaje de construcción el que no varía; aquél que, al mantenerse fiel a sí mismo, logra plegar dos tiempos en la historia. Sin embargo, este código está uncido sobre un material que le da cuerpo y sustento en cuanto a existencia empírica. Ésta es la sustancia, entonces, que se ve afectada por la secuencialidad de un tiempo que siempre es continuo, pese a las ondulaciones de la trama social.

Desde otra mirada, el panorama actual del consenso, al dejar fuera de plano a las miradas que se apartan de la oficialidad, requiere de dispositivos que recojan lo incompleto del pasado, las falencias de un discurso político que invisibiliza las extrapartes del trauma en orden a ahogar los lamentos de toda una generación tamizada por el "nunca más":

Les corresponde al arte y la literatura, al pensamiento crítico y la crítica cultural, recoger estas marcas de lo incompleto para que lo fisurado y lo residual del pasado cobre el espesor valorativo que les niegan los saberes totalizadores de la unidad, la síntesis y la recapitulación (Richard, 2010: 182).

El texto artístico es capaz de enunciar las fisuras de lo "no dicho" y de lo latente que se permea bajo las fuerzas enunciativas que suprimen la otredad y la discrepancia discursiva. Diagramas viene a responder desde una ética de extra-muros, afuerina al imperativo social que demanda un arte de la dictadura particular, cifrado y políticamente "denso". Sus contenidos problematizan la mirada estancada del discurso memorioso y señalan sus puntos de quiebre, sus grietas: los discursos hegemónicos del recuerdo sólo pueden desvincularse de su estancamiento enunciativo en tanto que pongan en tensión y discusión elementos ajenos a lo que ya está estipulado como archivo del recuerdo. Sólo mediante la recuperación y la re-activación de obras, discursos y registros rechazados por la oficialidad, el espesor de la memoria social puede ensanchar sus recursos del recuerdo, así como promover la escritura de nuevos discursos a partir de grupos sociales hasta ahora no legitimados. 
Para finalizar, se debe considerar el carácter plural y potencialmente infinito de Diagramas para enlazarlo con las problemáticas de la memoria. Todos los dibujos que componen la serie se posicionan en una contigüidad enunciativa que los categoriza como una sola gran obra, pues, si bien contienen diferencias formales y focos temporales distintos, han sido atravesados y conformados a partir de un mismo gesto ideológico, una misma pulsión expresiva o, sencillamente, un mismo código, que hemos llamado "atemporal".

En cada diagrama hay más de un elemento o figura, completa o cerrada en sí misma, junto a otra similar o diferente, pero que conforman con ella un todo en el que desaparecen sus partes. Así cumple el aserto de los psicólogos de la Gestalt, la ley general de la forma, que dice que "el todo es mucho más que una suma de partes" (Rivera-Scott, 2013: 68).

Esta idea de conjunto, en donde cada parte construye en igual medida un "segmento" del "todo" al cual pertenecen, hace referencia inmediata al concepto de memoria que se ha trabajado. Diagramas supone una constelación de signos, ritmos y variables coherentes entre sí, pero diferenciadas en sus particularidades individuales. Del mismo modo, la narración de la memoria queda establecida a partir de la complementariedad de partes, relatos, testimonios y archivos en pugna, los que entrecruzan y problematizan sus contenidos de verdad histórica a fin de entretejer, manteniendo sus diferencias, un gran manto, una urdimbre, un sistema, en fin, al que llamaremos "memoria social". Se debe cuidar, sin embargo, que la memoria, como un todo, no quede estancada en sus recursos de enunciación. Ésta, al igual que Diagramas, responde a una formación potencialmente infinita que debe actualizarse y nutrirse de la mayor cantidad de "partes" posibles, siempre bajo una mirada reconstitutiva que no aplane o desfigure las secciones bajo el manto de lo oficial. No sólo bastan, en ese sentido, las formas evidentes.

\section{Conclusión}

En la medida en que nos hemos adentrado en las interpretaciones de Diagramas, se han develado las huellas remanentes que subyacían a su estructura física, lugar que compete a su instancia misma de enunciación. Más allá de objetivar un análisis semiótico de las obras o de intentar aproximarnos a las intenciones - quizá inaccesibles - de su autor, el propósito de este artículo ha quedado correctamente estipulado al responder cabalmente a las metas que se propuso. De este modo, se puede concluir que Diagramas conforma una serie de textos artísticos que se desprenden del deber ético preestablecido por el campo consensuado de la memoria. Mediante un código que no interpela al trauma y que se cifra según sus propias reflexiones y propósitos formales, la obra pareciera ser más decidora del tiempo social que divide su producción que aquellas obras que trabajan la violencia, el dolor 
y la catástrofe desde la culposa trampa del arte comprometido. El llamado de atención, por tanto, será el de buscar la memoria no tan sólo a través de los archivos, obras y testimonios aceptados como pertinentes por la oficialidad, sino que excavar en la memoria de aquellos relatos y objetivaciones que se encuentran al margen. De acuerdo con este propósito, hemos puesto énfasis en la materia como receptor intrínseco de memoria: el papel como una plataforma en la que el tiempo moldea sus huellas y graba sus silenciosas pautas hacia el pasado. Vistos así, los recursos de la memoria amplían sus alcances hacia los rincones donde lo objetual y lo matérico nos aparecen como reservorios de narrativas ocultas. Se debe tener cuidado, entonces, de conceder a lo evidente el privilegio de la verdad histórica. Sólo mediante una interpretación que considere los factores enunciativos, la remanencia material, las intenciones particulares de los códigos cifrados en los que se encriptan los contenidos, en fin, la mayor cantidad de variables y de "partes", se conformará un discurso de la memoria, un "todo" que no suprima la textura heterogénea que presupone la reconfiguración viva de una trama social marcada por el trauma.

\section{Referencias}

Adorno, Theodor (2004) Teoría estética Trad. Jorge Navarro Pérez. Madrid: Akal.

Adrián, Jesús (2011). Heidegger y el olvido del cuerpo. Lectora: revista de dones i textualitat (17). 181-198.

Candau, Joel (2006) Antropología de la memoria. Buenos Aires: Nueva Visión.

Eco, Umberto (2013) Los límites de la interpretación. Barcelona: Debolsillo, Random House Mondadori.

Foucault, Michel (2002). La arqueología del saber. Buenos Aires: Siglo XXI.

Lira, Elizabeth (2010). Trauma, duelo, reparación y memoria. Revista de estudios sociales (36), Universidad de los Andes, Colombia. 14-28.

Lotman, Yuri (2011). Estructura del texto artístico. Madrid: Akal.

Navarrete, Sandra (2016). Las narraciones de la memoria y el otro: Notas sobre la pertinencia de una mirada socio-ética". Inédito.

Richard, Nelly (2010). Crítica de la memoria. Santiago: UDP.

(2014). Márgenes e instituciones. Arte en Chile desde 1973. Santiago: Metales Pesados.

Rivera-Scott, Hugo (2013). Diagramas: Cuaderno paradocente. Santiago: Vaticanochico / Ocho Libros. 